\title{
Compact Circularly Polarized Multiband Antennas for RFID Applications
}

\author{
H. M. El Misilmani, M. Al-Husseini, K. Y. Kabalan, and A. El-Hajj \\ ECE Department, American University of Beirut, P.O. Box 11-0236, Beirut 1107 2020, Lebanon \\ Correspondence should be addressed to H. M. El Misilmani; hilal.elmisilmani@ieee.org
}

Received 14 January 2014; Accepted 31 March 2014; Published 29 April 2014

Academic Editor: Christoph F. Mecklenbräuker

Copyright (C) 2014 H. M. El Misilmani et al. This is an open access article distributed under the Creative Commons Attribution License, which permits unrestricted use, distribution, and reproduction in any medium, provided the original work is properly cited.

\begin{abstract}
This paper presents multiband circularly polarized (CP) antennas for radio frequency identification (RFID). A coax-fed and a microstrip-line-fed antennas having optimized cross-slots in their patches are first designed for dual-band CP operation. The microstrip-line-fed design is then modified, by incorporating a U-shaped slot in its partial ground plane, to achieve additional operation band with a CP characteristic. Simulation and measured results of the presented designs are reported. The measured results are in accordance with the computed ones. The compact size and CP property make these designs suitable for RFID applications.
\end{abstract}

\section{Introduction}

Radio frequency identification (RFID) is dominating the new technologies through its advantage of using wireless noncontact radio communication, using radio frequency electromagnetic fields, to transfer data and information radio waves from a tag attached to an object, for the purposes of automatic identification and tracking [1]. RFID system consists of a reader (or interrogator), a tag (or transponder), and antennas. Designing antennas for RFID readers necessitates wideband, reconfigurable band, or multiband performance with circular polarization. The wideband, reconfigurable band, and the multiband are used to make the system operable in different applications and standards where circular polarization is meant to overcome problems such as absorption, phasing issues, multiphases, inclement weather, and line-of-sight path $[2,3]$. UWB antennas have the advantage of covering a very wide frequency range, but they are prone to noise from unwanted frequencies, which could degrade the original message [3]. On the other hand, reconfigurable antennas are designed to be able to control the resonance of the antenna and limit the disadvantage of UWB antennas. These reconfigurable antennas are complex as they require the use of switching elements and their biasing lines or other complicated reconfiguration mechanisms [3].
The resonant frequencies of the proposed antenna lie in the microwave frequency range. Karmakar et al. presented in [4] the development of a low-cost active RFID tag using an annular ring-slot antenna working at $2.4 \mathrm{GHz}$. Cao et al. presented a Minkowski fractal reader antenna composed of three layers, designed for handheld RFID reader systems working at $2.425 \mathrm{GHz}$ in [5]. In [6], Pitukwerakul et al. presented a channel of wooden and metal book shelves modeled for RFID library management system using microstrip antennas as both transmitter and receiver antennas working at $2.45 \mathrm{GHz}$. Popplewell et al. presented in [7] a completely integrated 5.2 GHz BFSK RFID transceiver suitable for RFID and medical sensor applications. In [8], Thiruvalar Selvan and Raghavan presented a coplanar-waveguide-fed spiral monopole antenna for RFID applications at $5.8 \mathrm{GHz}$. A small, low-cost hairpin antenna-in-package concept for RFID applications working around $6 \mathrm{GHz}$ is presented by Papatheologou et al. in [9].

Multiband circularly polarized (CP) antennas can be thought of as an intermediate solution combining simplicity and multifrequency operation. The advantage of the multiband circularly polarized antennas is to be able to integrate several frequency bands on one single antenna, making it useful for several frequency ranges. These multiband antennas could contain frequency ranges from several wireless 
applications, and hence the antenna could be used for several applications [10]. Another important feature in designing these antennas, achievable with the use of microstrip antennas, is to make them compact, lightweight, and low-cost antennas [11].

Due to the previously discussed advantages of multiband antennas, several designs with dual-band operation and circular polarization over the two bands have been presented. Achieving dual-band CP operation is a challenging task, especially when the ratio of the center frequencies of the two bands is large, that is when the two bands are spaced apart in the spectrum. Chen and Yung [12] proposed a unidirectional dual-band circularly polarized antenna working in $1.43-1.55$ and $2.09-2.53 \mathrm{GHz}$ bands, by loading a pair of L-shaped stubs outside a truncated patch. Heikkinen and Kivikoski [13] presented a dual-band CP microstrip-fed shorted ring-slot rectenna working at 2.45 and $5.8 \mathrm{GHz}$ where two shorted annular ring-slot antennas are combined in order to achieve a dual-CP operation. A dual-band circularly polarized microstrip antenna for China's Compass Navigation Satellite System is proposed by Bo et al. [14], with two pairs of T-shaped slots embedded close to the edge of the circular patch for achieving dual-band circularly polarized operation in two frequency bands 1610$1626 \mathrm{MHz}$ and $2483-2500 \mathrm{MHz}$. Liao et al. [15] presented a compact single-feed dual-band circularly polarized patch antenna with small frequency ratio consisting of an unequal cross-slot embedded in a circular patch and a narrow annular ring operating at 1.70 and $1.57 \mathrm{GHz}$. A dual-frequency circularly polarized microstrip antenna is also proposed by Wang [16]. The suggested antenna, operating at $1.575 \mathrm{GHz}$ and $2.492 \mathrm{GHz}$, has a structure of two microstrip board layers, employing two circular patches which have different radius in order to achieve the dual-band resonance [16]. Nayeri et al. [17] presented a single-feed dual-band circularly polarized microstrip antenna with a dual-stacked-patch configuration. The dual-CP operation is achieved by using asymmetrical Uslots on the patches and the antenna is operating at 3.5 and 5.8 GHz. Qian and Tang [18] presented a dual-band circularly polarized multilayer microstrip antenna for 3.5 and $5.2 \mathrm{GHz}$. In the proposed antenna, a stacked-patch configuration is used along with truncated corners and inserted slits of the hexagonal patches in order to achieve the dual-CP operation.

For RFID applications, a dual-band circularly polarized RFID antenna utilizing the feeding network with Wilkinson power divider is proposed by Shin et al. [19]. The design consists of two square radiating patches, an isolator for dual-band performance, a bottom ground plane, and microstrip feeding networks. The antenna is operating in the $860-960 \mathrm{MHz}$ and 2.4-2.48 GHz bands. Jung and Lee [20] presented a dualband circularly polarized aperture coupled microstrip RFID antenna using a metamaterial (MTM) branch-line coupler. The proposed antenna operates at $920 \mathrm{MHz}$ and $2.45 \mathrm{GHz}$. The radiating patch antenna is fed by the two output lines of the designed dual-band MTM branch-line coupler through two slots, and a cross-slot is implemented at the center of the radiating patch to enhance isolation. On the ground plane the slots are positioned in a T-shape in order to increase the isolation.

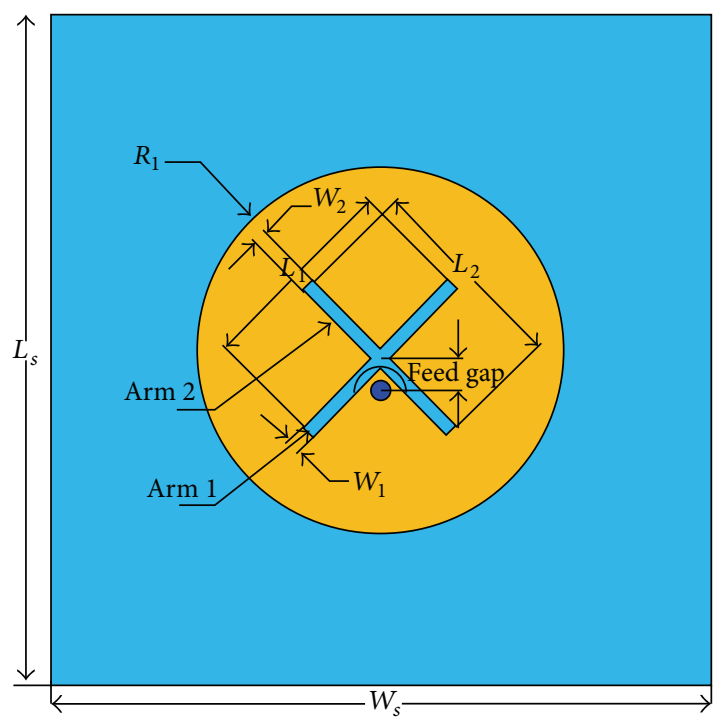

FIGURE 1: Configuration and parametrized dimensions of the coaxfed dual-band CP antenna.

Since the design goal is heading towards compact lightweight antennas, and due to the advantages of multiband antennas and circular polarization type previously discussed, the goal of this paper is to combine the multiband with circular polarization and study the design of several multiband circularly polarized antennas for RFIDs. Accordingly, this paper presents novel multiband circularly polarized antennas for radio frequency identification (RFID). The paper starts with a procedural overview on obtaining a dual-band characteristic along with dual-band circular polarization and move to present a multiband circularly polarized antenna. The antennas were simulated, fabricated, and tested. Similarity between the measured and the simulated results is shown in all cases.

\section{Design, Simulations, and Results}

2.1. Coax-Fed Dual-Band Circularly Polarized Antenna. The first antenna is based on a coax-fed circular patch with radius $R_{1}$ printed on an FR4 substrate with dimensions of $50 \times$ $50 \mathrm{~mm}^{2}$, a thickness of $1.6 \mathrm{~mm}$, and a dielectric constant $\epsilon_{r}$ of 4.4. A cross-slot with two arms of lengths $L_{1}$ and $L_{2}$ and widths $W_{1}$ and $W_{2}$ is incorporated on the patch. The configuration of this design is shown in Figure 1.

The circular polarization operation is generated when two degenerate orthogonal linearly polarized modes, of equal amplitude and $90^{\circ}$ phase difference, are independently excited. The cross-slot adopted here is one method that can lead to this operation, as a result of the reflection of the signals from the cross-arms with a $90^{\circ}$ phase shift, which results in $\mathrm{CP}$ radiation. However, to guarantee the $\mathrm{CP}$ operation, the arm lengths of the cross-slot have to be optimized, while preserving the sought resonance frequencies. Studies have shown that, to obtain CP, the lengths of the two arms should 


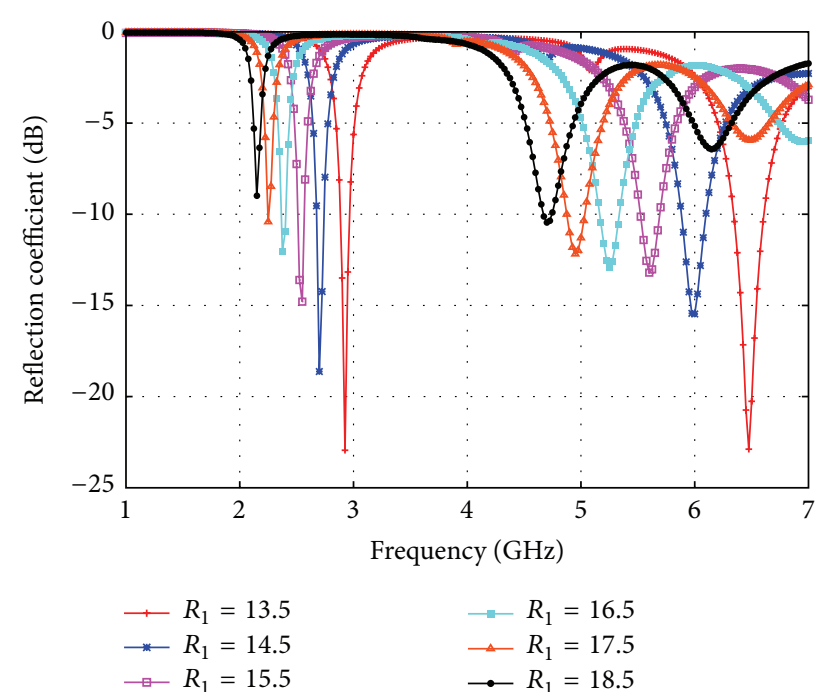

FIgURE 2: Simulations for different values of circular patch radius.

not be equal, or else the antenna will operate with a linear polarization.

Comparing the objective of this paper and the antenna introduced in [15], the difficulty in our case is to be able to achieve resonance in the $2.4 \mathrm{GHz}$ and a higher frequency in the 5.2-5.95 GHz band (large frequency ratio), which will require some heavy work on the parameters of the antenna, where each change in one parameter will affect not only the resonance frequency but the circular polarization as well. The antenna presented in [15] has equal arm widths and very close arm lengths in order to achieve a small frequency ratio of 1.1.

\subsection{Parametric Study}

2.2.1. Choosing the Appropriate Radius $R_{1}$. The first step in our design is to choose the appropriate radius to start with. Starting from a length of $10 \mathrm{~mm}$ for each arm of the crossslot with a width of $1 \mathrm{~mm}$ for each and a feed gap of $2 \mathrm{~mm}$, varying the radius of the patch $R_{1}$ starting from $13.5 \mathrm{~mm}$ to 18.5 , the best radius to start with is that of $15.5 \mathrm{~mm}$, giving two resonance frequencies in two bands that could be used for RFID, at $2.4 \mathrm{GHz}$ and in the $5.2-5.3 \mathrm{GHz}$ band, as shown in Figure 2.

2.2.2. Choosing the Appropriate Feed Gap. In the second step, the feed gap or the gap between the feeder and the center of the circular patch is investigated. The values for the length and width of the two arms are kept fixed, that is, $10 \mathrm{~mm}$ and $1 \mathrm{~mm}$ respectively. The value of $R_{1}$ is set to $15.5 \mathrm{~mm}$, which is obtained from the optimization in Section 2.2.1. Simulating the design while varying the feed gap value from $0.5 \mathrm{~mm}$ to $3 \mathrm{~mm}$, the resonance frequency is seen to be stable with little variations. As a result, the feed gap value of choice is one that results in similarly low S11 values for the two frequency bands. This value is found to be $2 \mathrm{~mm}$.
2.2.3. Studying the Effect of Arms Lengths. After choosing the value of the radius and feed gap, it is now feasible to study the effect of arms lengths. As stated above, the cross is one of the methods that could be used to get circular polarization. However the cross by itself cannot give circular polarization unless some specifications are taken into consideration. One of these specifications is the arm length. In order to have circular polarization the lengths of the two arms of the cross should not be equal. A simulation with equal arms lengths of $10 \mathrm{~mm}$ resulted in axial ratio of $>17.3 \mathrm{~dB}$ over all the frequency range and thus no circular polarization operation is achieved. In addition, each length is responsible for the frequency where a circular polarization is achieved, as will be seen in the following sections. The $\mathrm{CP}$ will result from the different lengths of the two perpendicular arms reflecting the current from the coaxial feed in 90-degree phase shift achieving circular polarization operation.

2.3. How to Get Dual-Band and Circular Polarization. The goal now is to achieve two resonance frequencies and circular polarization at $2.4 \mathrm{GHz}$. Following are the methods and steps which will be used:

(i) vary the length of arm $1\left(L_{1}\right)$,

(ii) vary the length of arm $2\left(L_{2}\right)$,

(iii) vary the width of arm $1\left(W_{1}\right)$,

(iv) vary the width of arm $2\left(W_{2}\right)$.

2.3.1. Vary the Length of Arm $1\left(L_{1}\right)$. Varying the length of arm $1\left(L_{1}\right)$ and keeping the other parameters constant, the best value to get circular polarization at approximately $2.4 \mathrm{GHz}$ with resonance at $2.4 \mathrm{GHz}$ and in the $5.4-5.575 \mathrm{GHz}$ band was noticed to be $15 \mathrm{~mm}$. In order to achieve an additional circular polarization operation in one frequency of the $5.2-5.95 \mathrm{GHz}$ band and enhance the circular polarization operation achieved at $2.4 \mathrm{GHz}$, the above mentioned steps are processed while keeping $L_{1}=15 \mathrm{~mm}$. The difficulty in this situation is that every parameter $\left(L_{1}, L_{2}, W_{1}\right.$, and $\left.W_{2}\right)$ will have major effect on the resonance and circular polarization operation.

2.3.2. Vary the Length of Arm $2\left(L_{2}\right)$. Keeping the widths of the two arms equal to $1 \mathrm{~mm}$ and varying the length of arm $2\left(L_{2}\right)$ while keeping the first one $\left(L_{1}\right)$ equal to $15 \mathrm{~mm}$, the best result is achieved at $L_{2}$ equal to $11.75 \mathrm{~mm}$. The antenna has three resonance frequencies, at $2.4,5.4-5.6$, and $5.95 \mathrm{GHz}$ (RFID frequencies), for which two of them have CP, 2.4 and $5.95 \mathrm{GHz}$.

2.3.3. Vary the Width of Arm $2\left(W_{2}\right)$. In order to further enhance the CP results, the two widths of arms $W_{1}$ and $W_{2}$ are changed. Starting with varying the width of arm $\left(W_{2}\right)$ while 


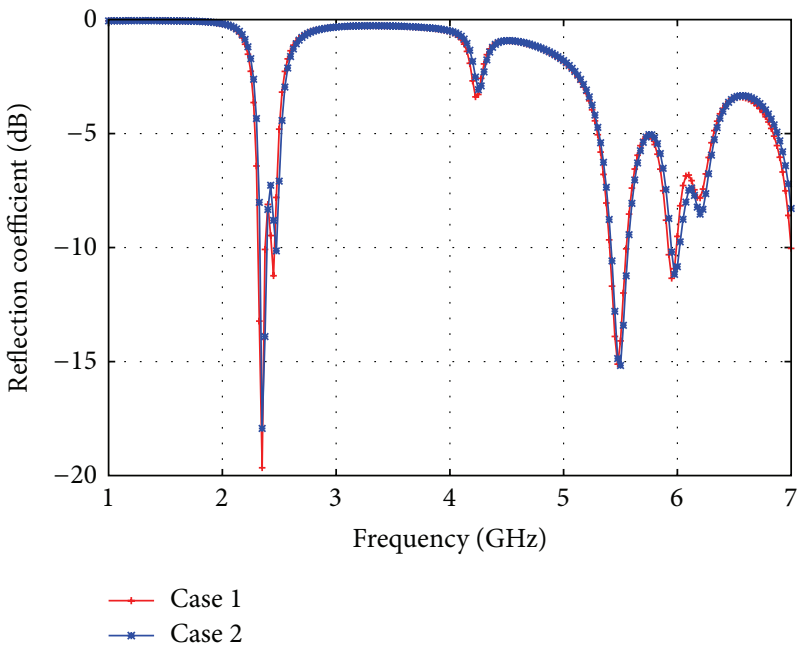

(a) Reflection coefficient S11

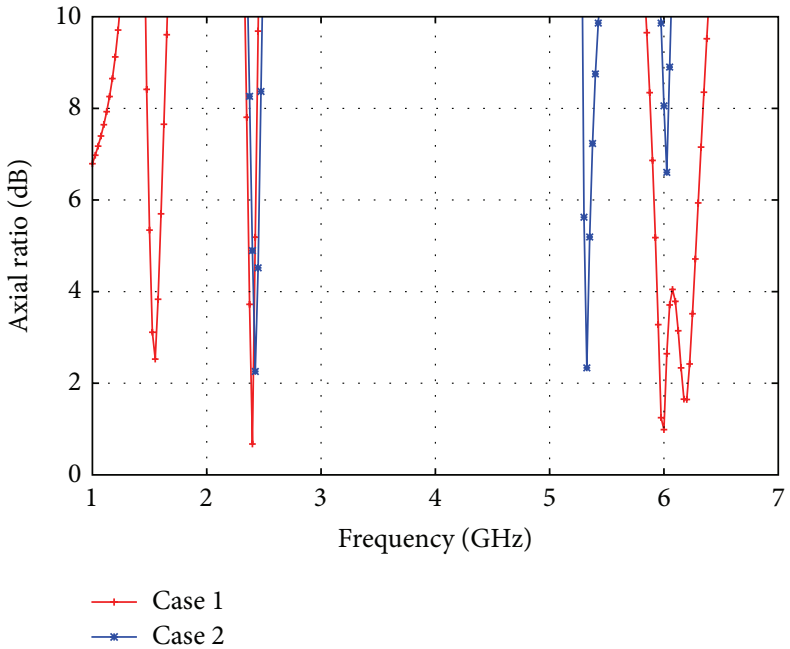

(b) Axial ratio

Figure 3: Coax-fed dual-band CP antenna S11 and axial ratio results.

TABLE 1: The parameters of the three coax-fed dual-band antenna cases.

\begin{tabular}{lcc}
\hline Parameters & $\begin{array}{c}\text { Case 1 } \\
\text { Size }(\mathrm{mm})\end{array}$ & $\begin{array}{c}\text { Case 2 } \\
\text { Size }(\mathrm{mm})\end{array}$ \\
\hline Arm 1 length $\left(L_{1}\right)$ & 15.25 & 15.25 \\
Arm 2 length $\left(L_{2}\right)$ & 12 & 12 \\
Arm 1 width $\left(W_{1}\right)$ & 1 & 0.9 \\
Arm 2 width $\left(W_{2}\right)$ & 0.8 & 0.6 \\
\hline
\end{tabular}

keeping the width of arm 1 equal to $1 \mathrm{~mm}$, the best results are achieved with the parameters presented in Table 1 (Case 1), for which the value of the lengths of arm 1 and arm $2\left(L_{1}\right.$ and $L_{2}$ ) had to be changed as well to accommodate for the change in the width of arm $2\left(W_{2}\right)$. The antenna has three resonance frequencies, at 2.4, 5.4-5.6, and 5.95-6 GHz (RFID frequencies), for which two of them have CP, at 2.4 and 5.95$6.03 \mathrm{GHz}$.

2.3.4. Vary the Width of Arm $1\left(W_{1}\right)$. After varying the length of arm $1\left(L_{1}\right)$, then the length of the second arm $\left(L_{2}\right)$, and then the width of arm $2\left(W_{2}\right)$ and after achieving two designs working on dual-frequency bands with circular polarization, in this step the width of $\operatorname{arm} 1\left(W_{1}\right)$ is varied. It is important to note here that changing the value of the width of the second arm will affect the total results, and thus some enhancement in the other parameters should be done in order to achieve the dual-band and circular polarization operation. Focusing on the widths parameters, it is seen that a dual-band characteristic with circular polarization could be achieved by the use of $0.9 \mathrm{~mm}$ and $0.6 \mathrm{~mm}$ values for arm 1 and 2 widths, respectively. Table 1 (Case 2) lists the parameters of this second dual-band CP antenna design having dual-band resonance with circular polarization at 2.425 and $5.325 \mathrm{GHz}$.
TABLE 2: Dual-band antenna parameters.

\begin{tabular}{lc}
\hline Parameter & Size $(\mathrm{mm})$ \\
\hline$R_{1}$ & 15.5 \\
$W_{f}$ & 3 \\
$L_{f}$ & 12.06 \\
Arm 1 length $\left(L_{1}\right)$ & 15.25 \\
Arm 2 length $\left(L_{2}\right)$ & 11.75 \\
Arm 1 width $\left(W_{1}\right)$ & 1 \\
Arm 2 width $\left(W_{2}\right)$ & 1 \\
\hline
\end{tabular}

The corresponding reflection coefficient S11 and axial ratio results for the two final dual-band antennas are shown in Figures 3(a) and 3(b). Case 1 has resonance frequencies and $\mathrm{CP}$ in the 2.4 and the $5.95-6 \mathrm{GHz}$ bands (both can be used for RFIDs). Case 2 reveals that a small change in the crossslot widths leads to a variation in the circular polarization operation in the higher band, where the new CP is achieved at $5.325 \mathrm{GHz}$ instead of $5.95 \mathrm{GHz}$.

2.4. Microstrip-Line-Fed Dual-Band Circularly Polarized Antenna. The second antenna is based on a microstrip-line feed and also has a cross-slot incorporated in a circular patch. An initial design of this antenna is shown in Figure 4(a). Simulating the new design using the parameters listed in Table 2 resulted in poor S11 and axial ratio results compared to those of the coax-fed dual-band antenna designed in Section 2.1. To obtain dual-band CP operation with this design, the cross-slot dimensions have to be optimized but this requires bulky work, or, as we did, the feed-patch connection could be further enhanced. Using the feed line in Figure 4(a) a large portion of EM waves is confined in the end part of the feed, and this degrades the S11 and the axial ratio results. To accommodate for this issue and allow larger 


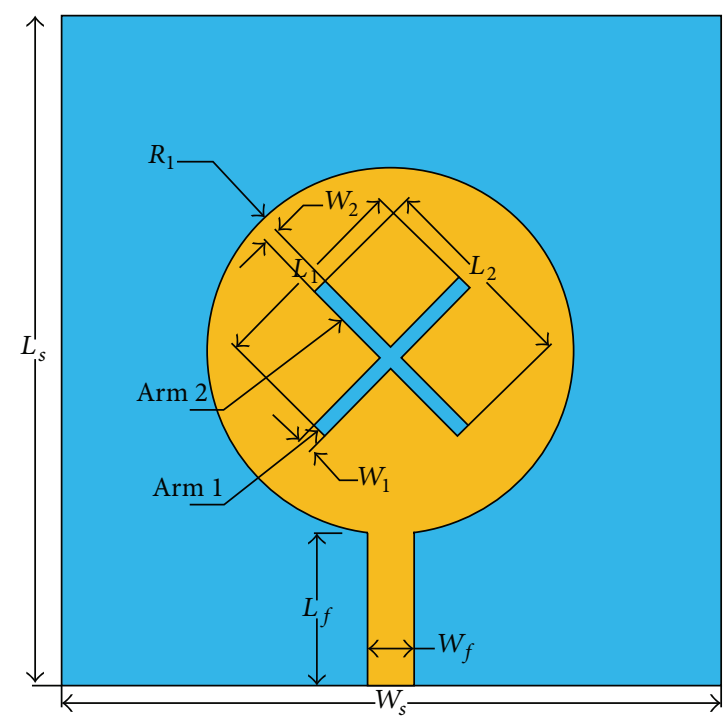

(a) Initial microstrip feed line

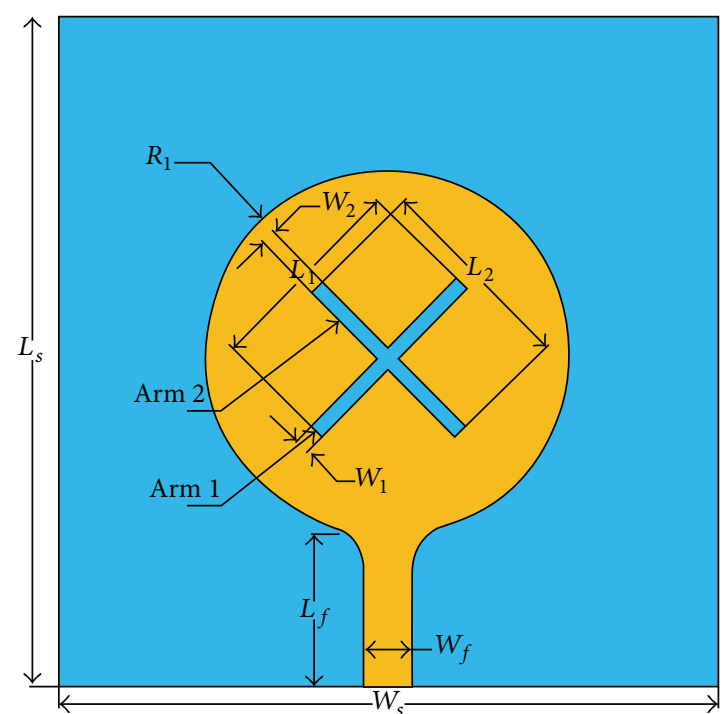

(b) Enhanced microstrip feed line

FIGURE 4: New dual-band design with microstrip feed line.

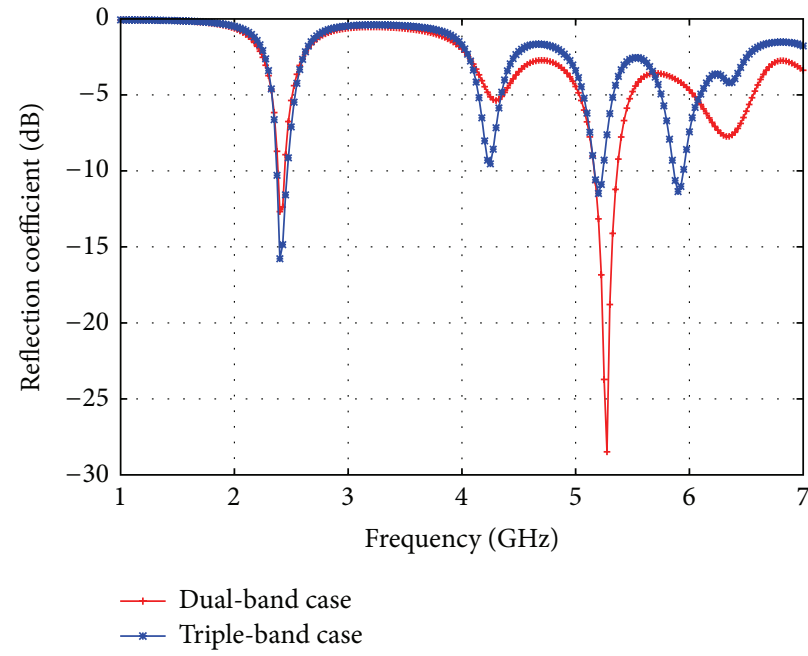

(a) Reflection coefficient

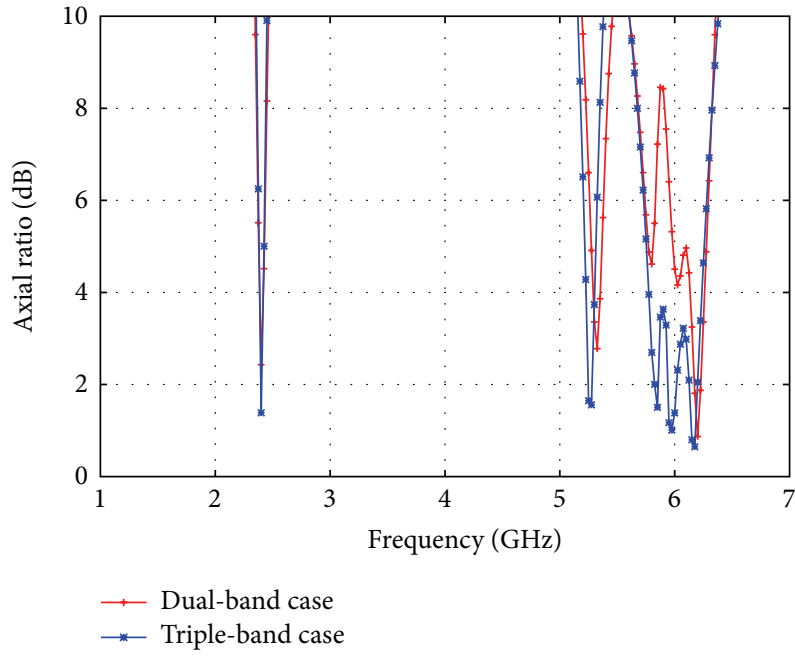

(b) Axial ratio

FIGURE 5: Dual- versus multiband microstrip-fed antennas S11 and axial ratio simulated results.

portion of EM to reach the cross, curved edges were added to the end of feed line as shown in Figure 4(b). In this way, more EM waves are now reaching the cross to be able to get good resonance and circular polarization results. This smooth transition between the microstrip feed and the patch helps to improve the S11 parameter, and with the two arms of the slot having different lengths, $\mathrm{CP}$ operation in two bands can be obtained.

Simulating the enhanced antenna with the parameters indicated in Table 2, two resonance frequencies have been achieved, one in $2.38-2.45 \mathrm{GHz}$ band and another in 5.2$5.375 \mathrm{GHz}$ both with circular polarization, as shown in Figures 5(a) and 5(b).
2.5. Microstrip-Line-Fed Multiband Circularly Polarized Antenna. The first two antennas were dual-band CP. This third design aims at having $\mathrm{CP}$ in a third band. This can be done through defecting the ground plane by etching a U-shaped slot, as the one used by the author in [21]. This slot in the ground is used to radiate in an additional frequency according to the its dimensions. Care should be taken to properly design this slot to have resonance and $\mathrm{CP}$ at the added resonant frequency. In this case, the slot dimensions have been optimized to have resonance at 5.85 and $5.95 \mathrm{GHz}$.

Investigating the effect of the slot on the operation of the antenna, the optimal performance was seen with the design and parameters shown in Figure 6(a). The fabricated antenna 


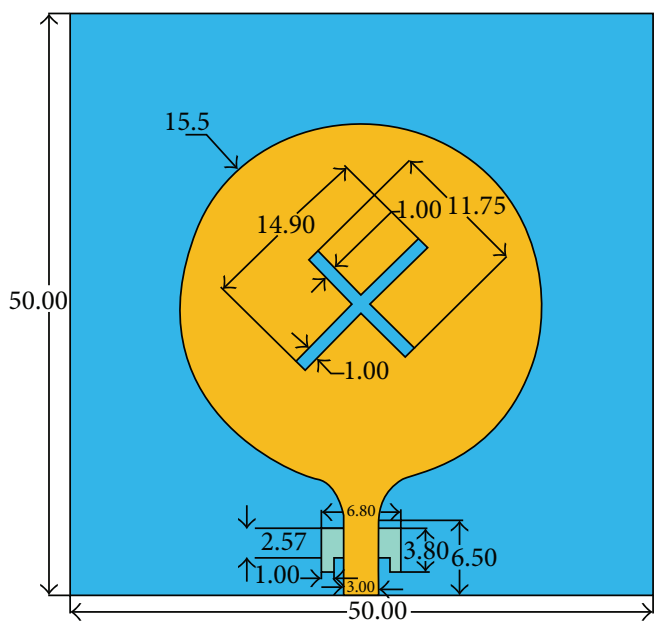

(a) Antenna parameters

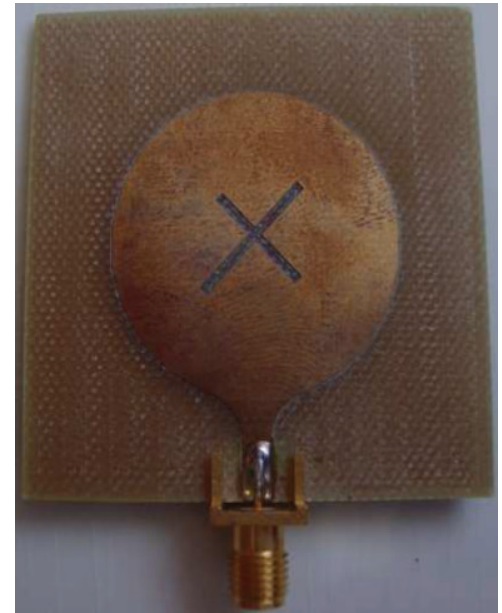

(b) Fabricated: top view

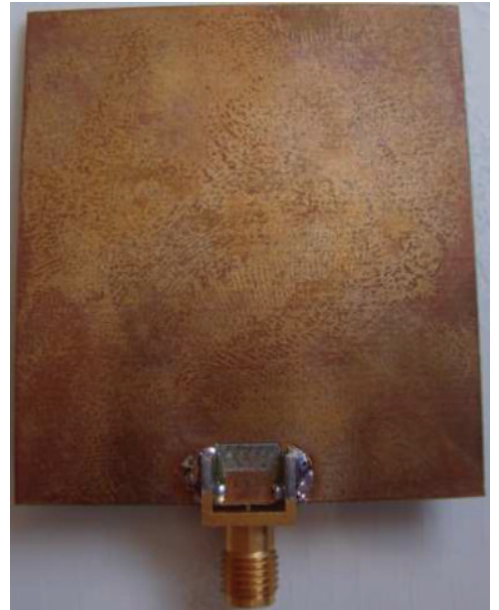

(c) Fabricated: bottom view

FIgURE 6: Multiband antenna, (a) antenna parameters, and fabricated antenna: (b) top view and (c) bottom view.

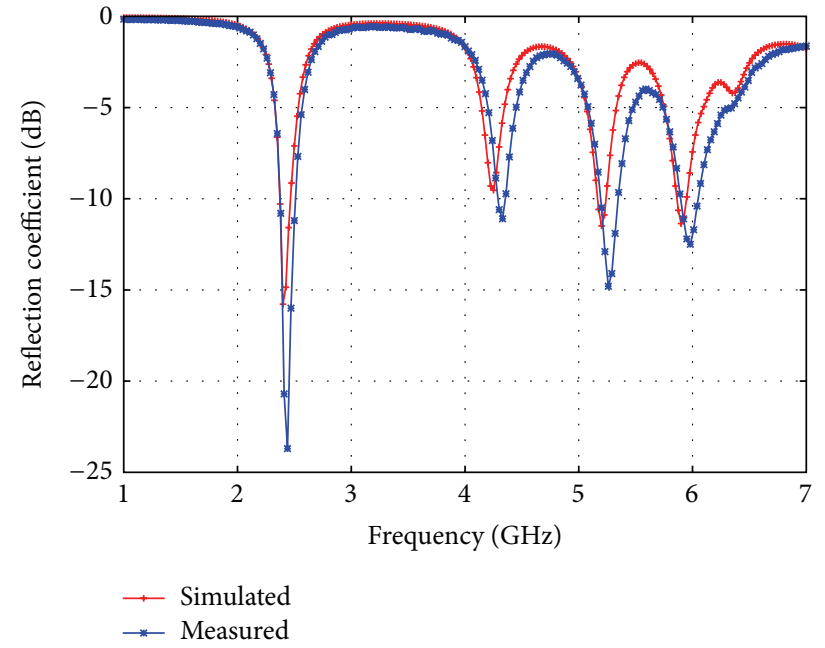

(a) Reflection coefficient

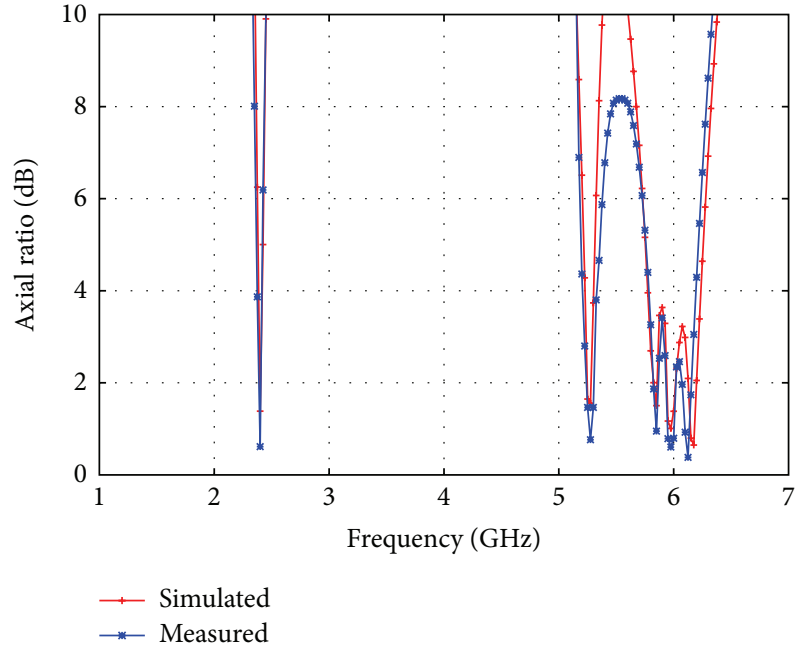

(b) Axial ratio

FIGURE 7: Multiband CP antenna S11 and axial ratio simulated versus measured results.

is shown in Figures 6(b) and 6(c). The compared dual- and multiband S11 and axial ratio simulated results are shown in Figure 5. Clearly, an additional band has been added to the operating bands of the antenna in the range of 5.8 to $5.95 \mathrm{GHz}$. Also, the measured and simulated S11 and axial ratio results of the multiband antenna are shown in Figures 7(a) and 7(b). The gain patterns, simulated and measured, at each resonant frequency, are indicated in Figure 8. As can be seen, the antenna has directional patterns, with gain of 3.257, 2.218, 3.406, and $3.703 \mathrm{~dB}$ at $2.4,5.25,5.85$, and $5.95 \mathrm{GHz}$, respectively. The antenna is RHCP, with the current distribution at different resonant frequencies being also shown in Figures 9 and 10. The antenna efficiency ranges between $43.03 \%$ and $50.21 \%$.

As can be seen, a good analogy is revealed between the simulated and measured results, and a new multiband circularly polarized antenna is achieved, operating at 2.4, $5.25,5.85$, and $5.95 \mathrm{GHz}$, making it suitable for multiband circularly polarized RFID applications operating at these frequencies. The 2.4 and $5.25 \mathrm{GHz}$ resonant frequencies with circular polarization have been accomplished through the use of different arms lengths and widths of a cross-slot embedded on a circular patch fed by a microstrip feed line. The higher resonant frequencies, 5.85 and $5.95 \mathrm{GHz}$ with 


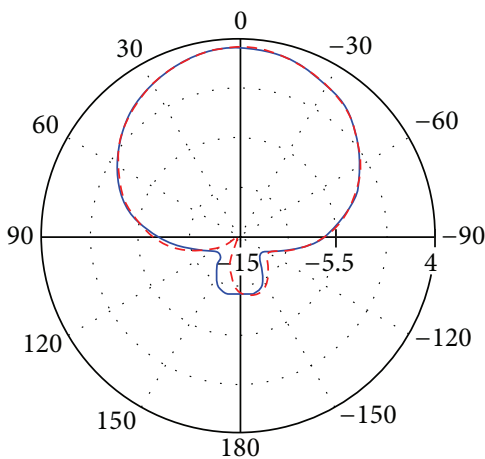

(a) $2.4 \mathrm{GHz}, \phi=0^{\circ}$

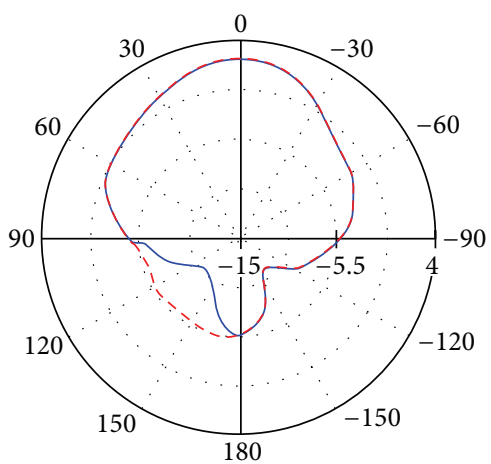

(c) $5.25 \mathrm{GHz}, \phi=0^{\circ}$

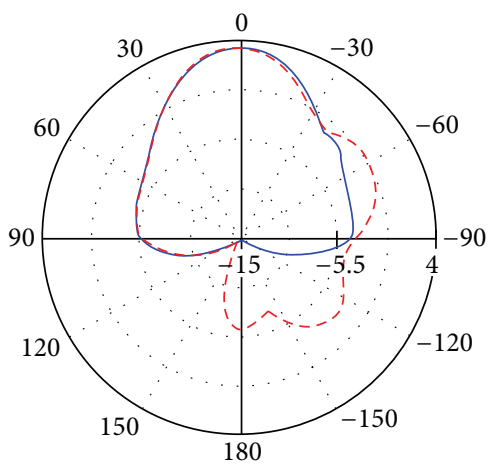

(e) $5.85 \mathrm{GHz}, \phi=0^{\circ}$

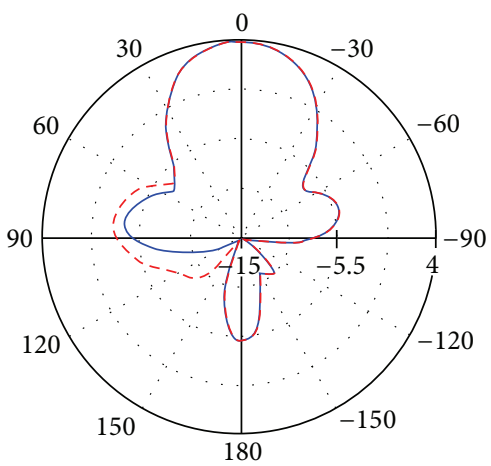

_- Simulated results

(g) $5.95 \mathrm{GHz}, \phi=0^{\circ}$

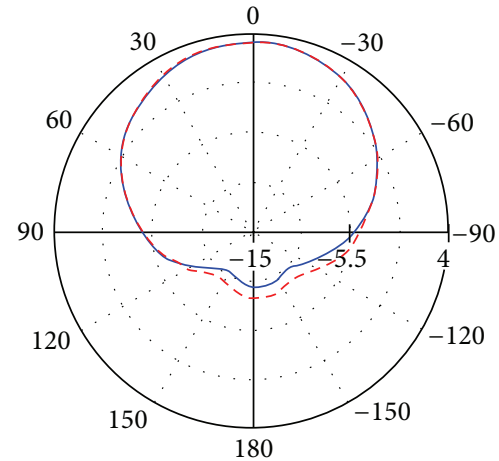

(b) $2.4 \mathrm{GHz}, \phi=90^{\circ}$

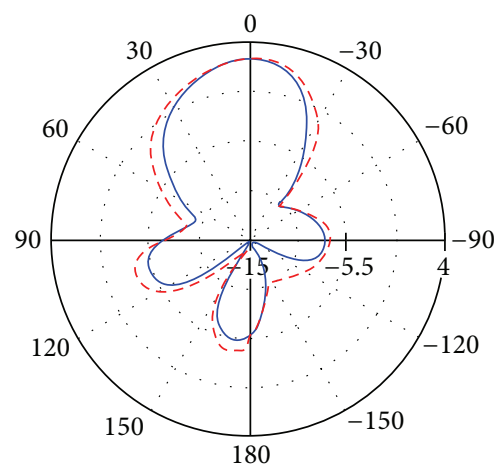

(d) $5.25 \mathrm{GHz}, \phi=90^{\circ}$

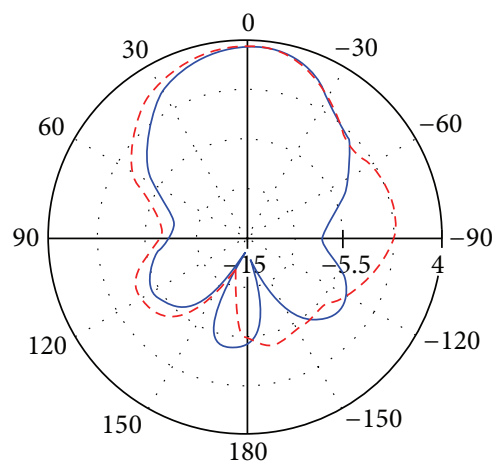

(f) $5.85 \mathrm{GHz}, \phi=90^{\circ}$

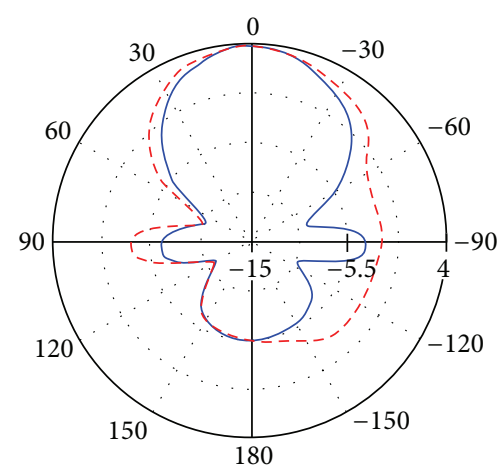

— Simulated results

- - - Measured results

(h) $5.95 \mathrm{GHz}, \phi=90^{\circ}$

FIGURE 8: Gain patterns at different resonant frequencies in both E- and H-planes. 


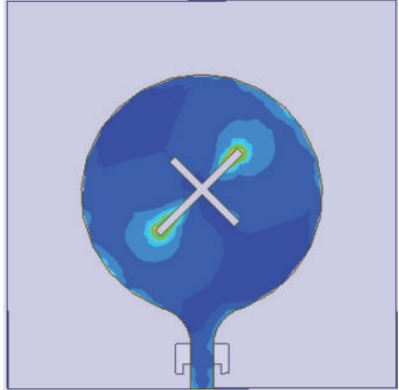

(a) $2.4 \mathrm{GHz}$, phase $=0^{\circ}$

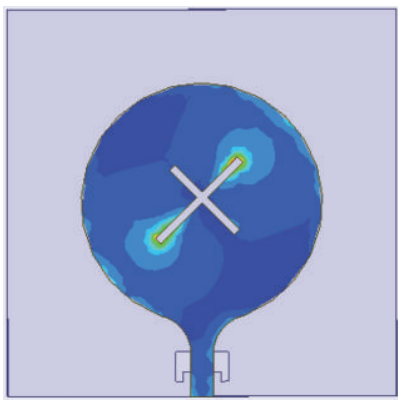

(c) $2.4 \mathrm{GHz}$, phase $=180^{\circ}$

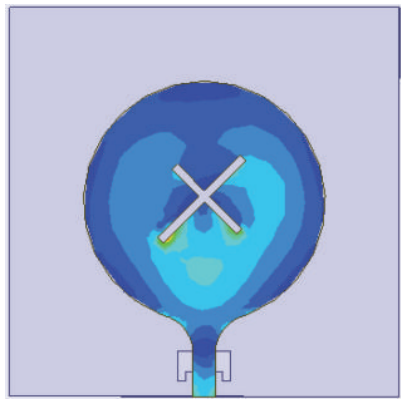

(e) $5.25 \mathrm{GHz}$, phase $=0^{\circ}$

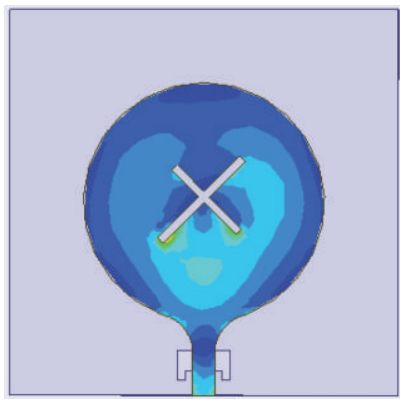

(g) $5.25 \mathrm{GHz}$, phase $=180^{\circ}$

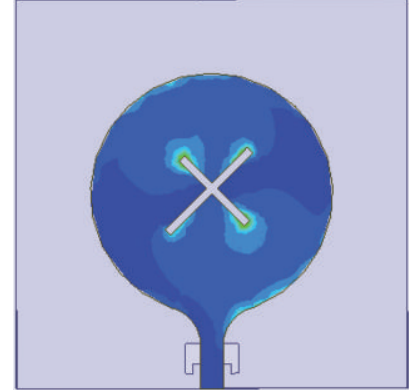

(b) $2.4 \mathrm{GHz}$, phase $=90^{\circ}$

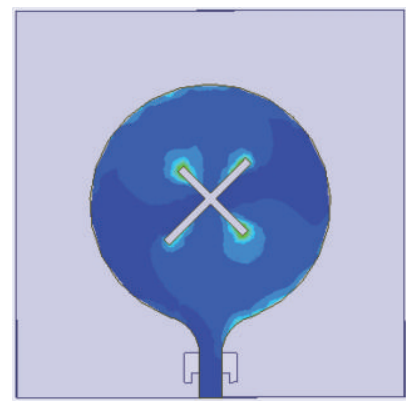

(d) $2.4 \mathrm{GHz}$, phase $=270^{\circ}$

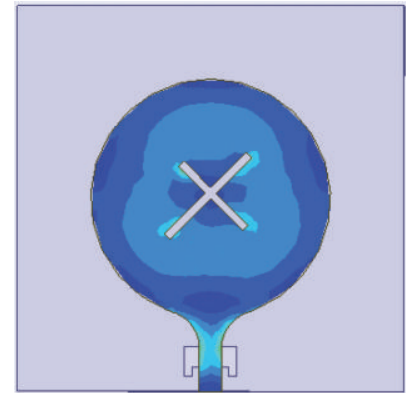

(f) $5.25 \mathrm{GHz}$, phase $=90^{\circ}$

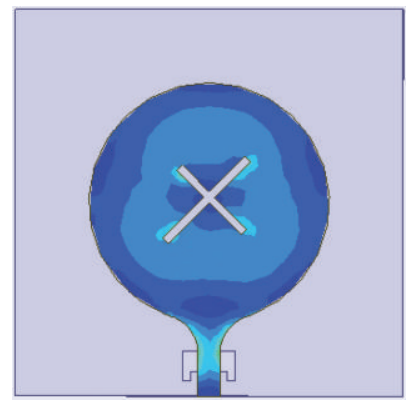

(h) $5.25 \mathrm{GHz}$, phase $=270^{\circ}$

FIGURE 9: Current distribution at 2.4 and $5.25 \mathrm{GHz}$ resonant frequencies for different phases.

circular polarization, have been achieved through etching the ground by U-slot shape.

\section{Conclusion}

In this paper, compact dual- and multiband circularly polarized antennas for radio frequency identification (RFID) were presented. A coax-fed dual-band CP antenna was first designed with the use of cross-slots etched in a circular patch. By changing the coax feed into a microstrip-line feed, a dual-band CP operation was obtained by smoothing and optimizing the connection between the microstrip line and the patch. The microstrip-line-fed design was then modified to get a third operation band with a CP characteristic, by incorporating a U-shaped slot in its partial ground plane. 


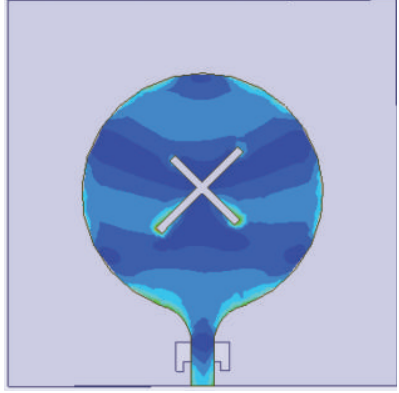

(a) $5.85 \mathrm{GHz}$, phase $=0^{\circ}$

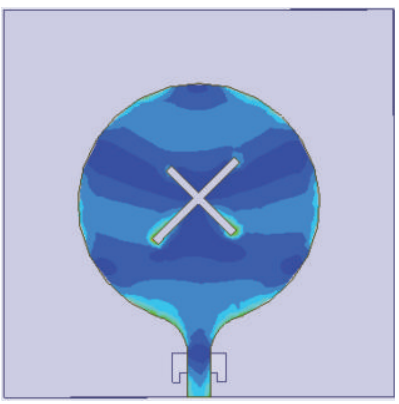

(c) $5.85 \mathrm{GHz}$, phase $=180^{\circ}$

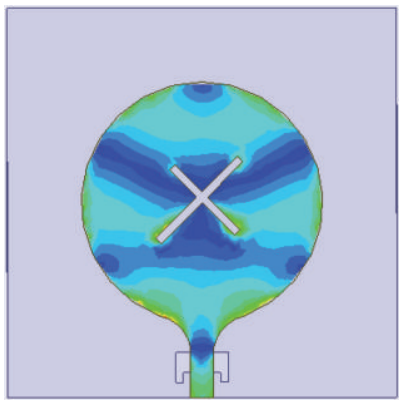

(e) $5.95 \mathrm{GHz}$, phase $=0^{\circ}$

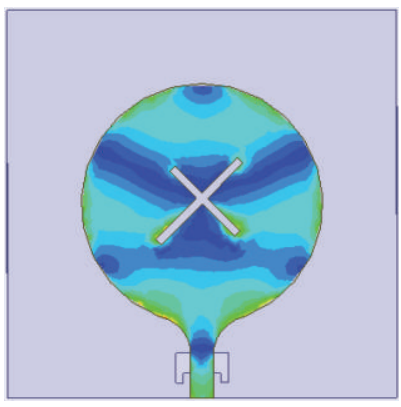

(g) $5.95 \mathrm{GHz}$, phase $=180^{\circ}$

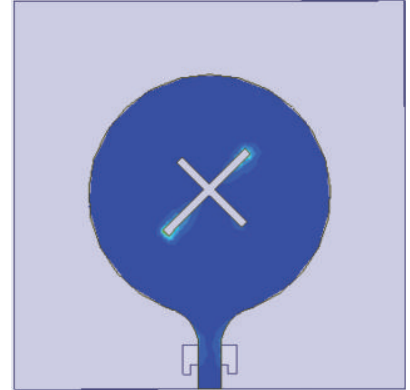

(b) $5.85 \mathrm{GHz}$, phase $=90^{\circ}$

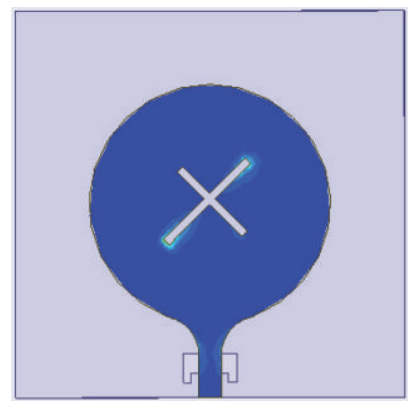

(d) $5.85 \mathrm{GHz}$, phase $=270^{\circ}$

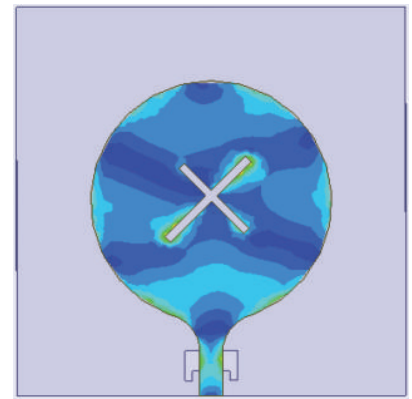

(f) $5.95 \mathrm{GHz}$, phase $=90^{\circ}$

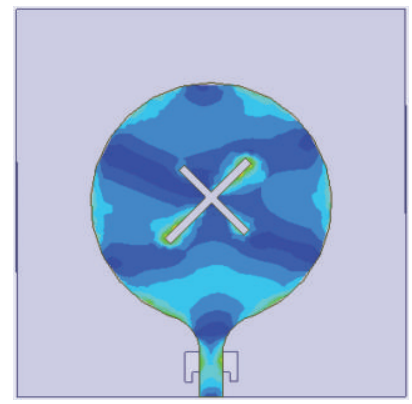

(h) $5.95 \mathrm{GHz}$, phase $=270^{\circ}$

Figure 10: Current distribution at 5.85 and $5.95 \mathrm{GHz}$ resonant frequencies for different phases.

\section{Conflict of Interests}

The authors declare that there is no conflict of interests regarding the publication of this paper.

\section{References}

[1] P. Fuhrer, D. Guinard, and O. Liechti, "RFID: from concepts to concrete implementation," in Proceedings of the International 
Conference on Advances in the Internet, Processing, Systems and Interdisciplinary Research (IPSI '06), Marbella, Spain, February 2006.

[2] K. Fujimot, Mobile Antenna Systems Handbook, Artech House, Norwood, Mass, USA, 3rd edition, 2008.

[3] D. Dardari, R. D’Errico, C. Roblin, A. Sibille, and M. Z. Win, "Ultrawide bandwidth RFID: the next generation?" Proceedings of the IEEE, vol. 98, no. 9, pp. 1570-1582, 2010.

[4] N. C. Karmakar, S. M. Roy, S. Preradovic, T. D. Vo, and S. Jenvey, "Development of low-cost active RFID tag at $2.4 \mathrm{GHz}$," in Proceedings of the 36th European Microwave Conference (EuMC '06), pp. 1602-1605, September 2006.

[5] L. Cao, S. Yan, and H. Yang, "Study and design of a modified fractal antenna for RFID applications," in Proceedings of the 2nd ISECS International Colloquium on Computing, Communication, Control, and Management (CCCM '09), pp. 8-11, August 2009.

[6] J. Pitukwerakul, P. Supanakoon, and S. Promwong, "Evaluation scheme RFID channel in library with wooden and metal book shelves based on measurement data," in Proceedings of the 7th Annual International Conference on Electrical Engineering/Electronics, Computer, Telecommunications and Information Technology (ECTI-CON '10), pp. 988-991, May 2010.

[7] P. H. R. Popplewell, V. Karam, A. Shamim, J. Rogers, and C. Plett, "An injection-locked $5.2 \mathrm{GHz}$ SoC transceiver with on-chip antenna for self-powered RFID and medical sensor applications," in Proceedings of the Symposium on VLSI Circuits (VLSIC '07), pp. 88-89, June 2007.

[8] P. Thiruvalar Selvan and S. Raghavan, "CPW—fed folded spiral strip monopole slot antenna for 5.8 GHz RFID Application," in Applied Electromagnetics Conference (AEMC '09), ind, December 2009.

[9] T. Papatheologou, A. B. Smolders, and U. Johannsen, "A hairpin Antenna-in-Package concept for RFID tag applications," in Proceedings of the IEEE Radio and Wireless Symposium (RWS '11), pp. 54-57, January 2011.

[10] A. T. Mobashsher, M. T. Islam, and N. Misran, "RFID technology: perspectives and technical considerations of microstrip antennas for multi-band RFID reader operation," in Current Trends and Challenges in RFID, chapter 5, Intech, 2011.

[11] D. M. Pozar and D. H. Schaubert, Microstrip Antennas: The Analysis and Design of Microstrip Antennas and Arrays, John Wiley \& Sons, Hoboken, NJ, USA, 1995.

[12] C.-H. Chen and E. K. N. Yung, "A novel unidirectional dualband circularly-polarized patch antenna," IEEE Transactions on Antennas and Propagation, vol. 59, no. 8, pp. 3052-3057, 2011.

[13] J. Heikkinen and M. Kivikoski, "Dual-band circularly polarized microstrip-fed shorted ring-slot rectenna," in Proceedings of the 6th International Symposium on in Antennas, Propagation and EM Theory, pp. 7-10, Tampere, Finland, October 2003.

[14] L. Bo, Y. Guan, Y. Jiang, and A. Zhang, "Compact dual band and circularly polarized microstrip antenna for CNSS," in Proceedings of the Cross Strait Quad-Regional Radio Science and Wireless Technology Conference (CSQRWC'11), pp. 401-403, Xian, China, July 2011.

[15] W. Liao, Q.-X. Chu, and S. Du, "A small frequency ratio dualband circularly polarized microstrip antenna," in Proceedings of the Asia Pacific Microwave Conference (APMC '09), pp. 27982801, Guangzhou, China, December 2009.

[16] L.-L. Wang, "The design and simulation of dual-frequency circularly polarized microstrip antenna," in Proceedings of the 9th International Symposium on Antennas Propagation and EM Theory (ISAPE '10), pp. 87-89, Xian, China, December 2010.

[17] P. Nayeri, K.-F. Lee, A. Z. Elsherbeni, and F. Yang, "Dualband circularly polarized antennas using stacked patches with asymmetric u-slots," IEEE Antennas and Wireless Propagation Letters, vol. 10, pp. 492-495, 2011.

[18] K. Qian and X. Tang, "Compact LTCC dual-band circularly polarized perturbed hexagonal microstrip antenna," IEEE Antennas and Wireless Propagation Letters, vol. 10, pp. 1212-1215, 2011.

[19] D. Shin, P. Park, J. Kim, W. Seong, and J. Choi, "A novel dualband circularly polarized antenna using a feeding configuration for RFID reader," in Proceedings of the International Conference on Electromagnetics in Advanced Applications (ICEAA '07), pp. 511-514, Torino, Italy, September 2007.

[20] Y.-K. Jung and B. Lee, "Dual-band circularly polarized microstrip RFID reader antenna using metamaterial branchline coupler," IEEE Transactions on Antennas and Propagation, vol. 60, no. 2, pp. 786-791, 2012.

[21] H. M. El Misilmani, M. Al-Husseini, and K. Y. Kabalan, "A simple miniaturized triple-band antenna for WLAN/WiMAX applications," in Proceedings of the Progress in Electromagnetics Research Symposium (PIERS), Moscow, Russia, August 2012. 

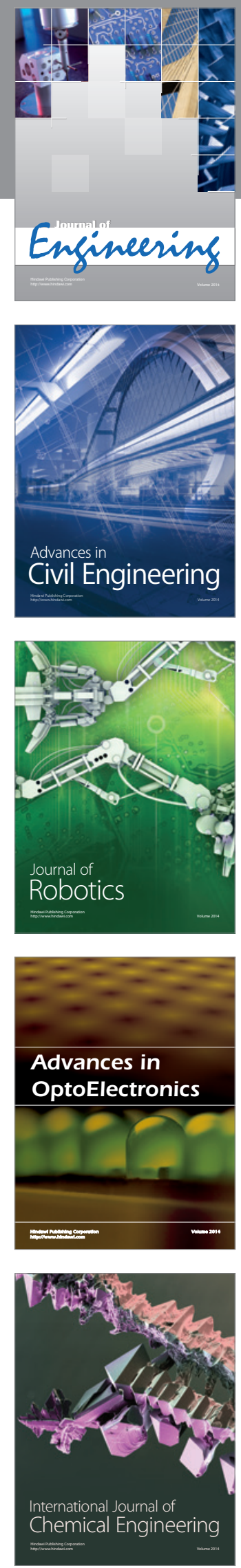

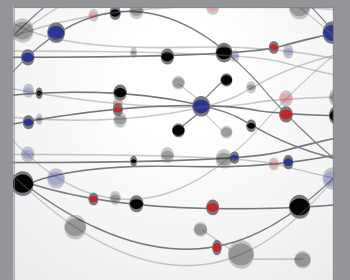

The Scientific World Journal
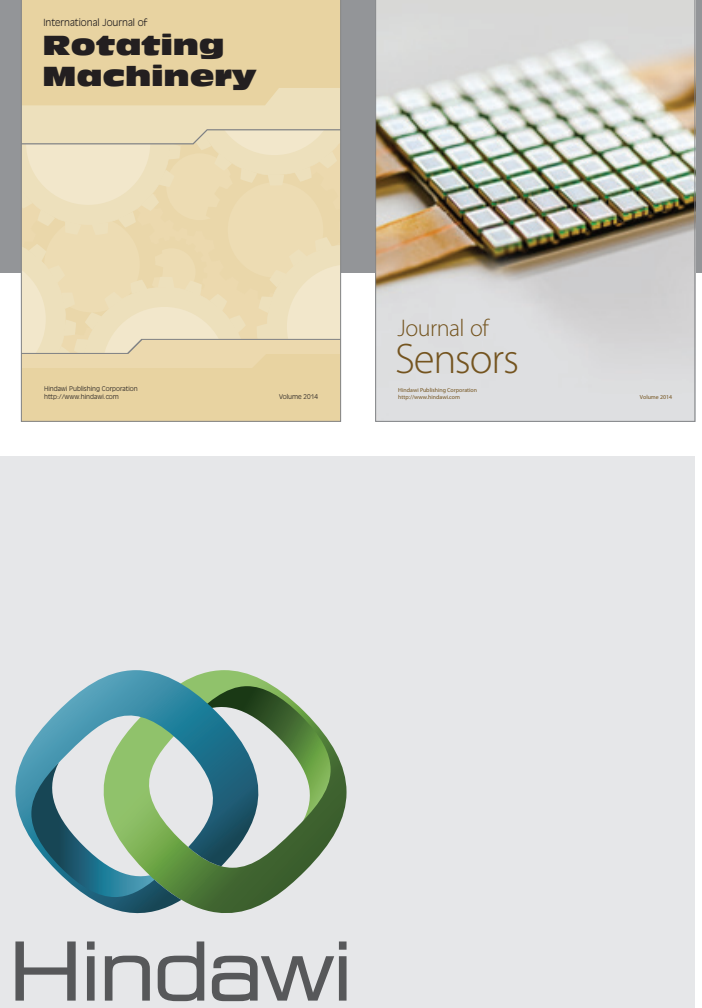

Submit your manuscripts at http://www.hindawi.com
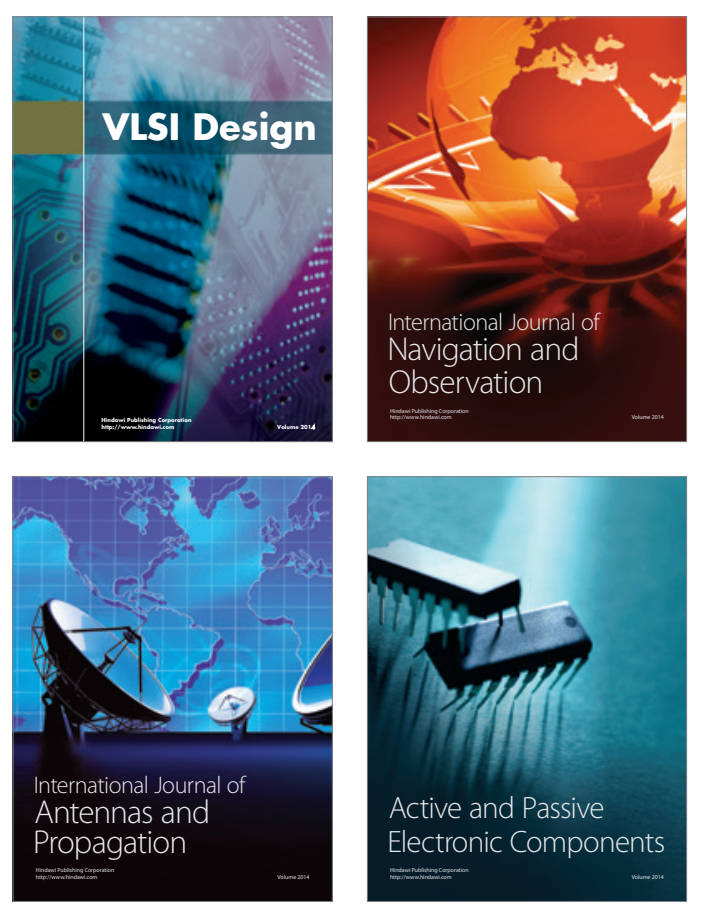
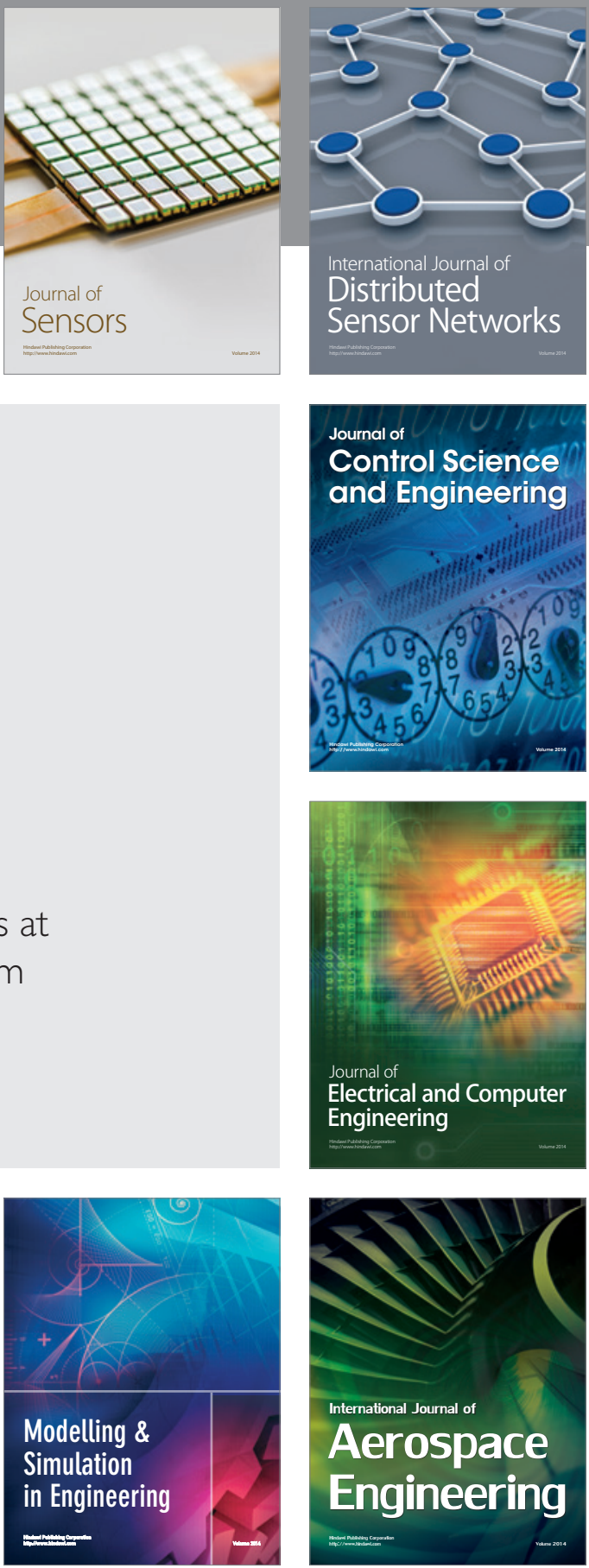

Journal of

Control Science

and Engineering
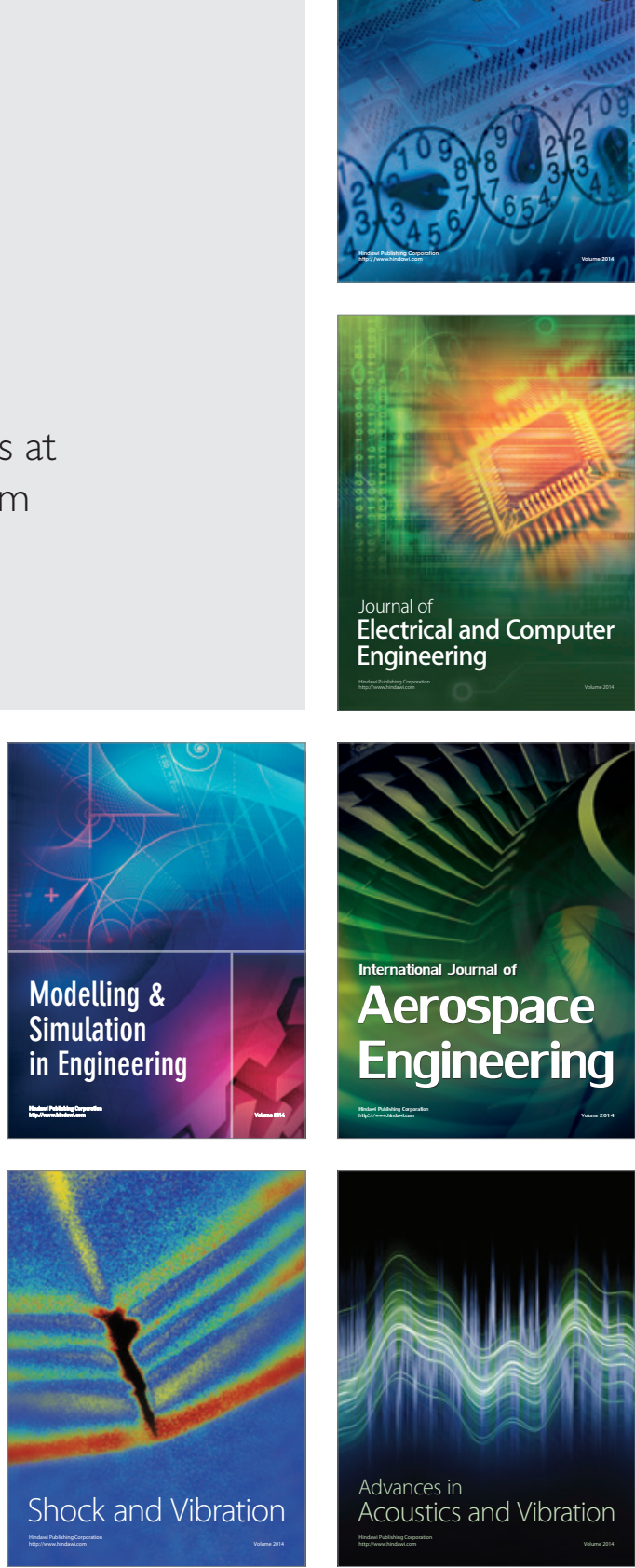